\begin{tabular}{l|l} 
Postprint Version & 1.0 \\
\hline $\begin{array}{l}\text { Journal website } \\
\text { Pubmed link }\end{array}$ & http://www.informaworld.com/smpp/title $\sim$ content $=\mathrm{t} 713648133 \sim \mathrm{db}=\mathrm{all}$ \\
\hline DOI & $10.1080 / 14768320500537639$
\end{tabular}

\title{
Situational aspects are more important in shaping proactive coping behaviour than individual characteristics: A vignette study among adults preparing for ageing
}

\author{
CAROLIJN OUWEHAND, DENISE T. D. DE RIDDER, \& JOZIEN M. BENSING
}

Department of Health Psychology, Utrecht University, Utrecht, The Netherlands Correspondence: Carolijn Ouwehand, Utrecht University, Department of Health Psychology P.O. Box 80.140, 3508 TC Utrecht, The Netherlands. Tel.: p31 (0) 30253 1470. Fax: p31 (0) 30253 4718. Email: c.ouwehand@fss.uu.nl

\begin{abstract}
It seems likely that proactive coping is an important mechanism for dealing successfully with threats to personal goals, yet little empirical research has been conducted in relation to this concept. The aim of the present study is to examine to what extent proactive coping is influenced by situation-specific features as well as by personal characteristics. Three vignettes, each representing a potential decline in an important resource (health, social relationships and finance), were presented to 123 adults between 50 and 70 years old. Multilevel analyses show that proactive coping is highly variable within persons and that three situational factors (type of stressor, appraised threat and appraised control) affected the employment of proactive coping strategies. Future temporal orientation was identified as a significant, positive predictor of proactive coping, but none of the other personal factors were found to be relevant.
\end{abstract}

\section{INTRODUCTION}

Proactive coping, or attempting to prevent potential stressors emerging, may be an important strategy in successfully preparing for difficult changes and events, which threaten personal goals or general well-being. Aspinwall and Taylor (1997) have argued that proactive coping probably has at least four advantages over reactive coping. Firstly, as proactive coping is directed at avoiding a future stressor or minimizing its effects, feelings of distress may decrease as well. Secondly, a related potential benefit is that chronic stress is kept under control. Since chronic stress is often the result of an accumulation of stressors, offsetting stressful events at an early stage may prevent chronic stress from developing. Thirdly, it is likely that the proportion of available coping resources to the strength of the stressor will be greater, because an emerging stressor is often modest and resources have not yet been used up. Finally, many coping options may still be present when proactive coping strategies are employed, as stressors are confronted before they are fully developed.

It is useful to note that opinions differ about the definition of proactive coping and the strategies it encompasses. Some researchers have described proactive coping as creating opportunities for personal growth and building up resources that facilitate the pursuit of challenging goals (Greenglass, 2002; Schwarzer, 2001; Schwarzer \& Taubert, 2002) while others have concentrated on the efforts that may help to prevent future threats to personal goals (Aspinwall, 1997; Aspinwall \& Taylor, 1997). 
Ouwehand, C., Ridder, D.T.D. de, Bensing, J.M.

Situational aspects are more important in shaping proactive coping behaviour than

individual characteristics: a vignette study among adults preparing for ageing

Psychology and Health: 21, 2006, nr. 6, p. 809-825

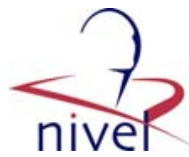

Although both types of proactivity merit examination, this article focuses on the definition of proactive coping as the strategies that are employed to detect and prevent probable stressors that threaten goals (Aspinwall, 1997). This process is sometimes labelled as preventive coping (e.g., Schwarzer, 2001). As such, our concept of proactive coping reverses the typical causal direction of the stress-coping relationship (Aspinwall \& Taylor, 1997). Proactive coping refers to the use of strategies when stress is still minimal, whereas reactive coping involves the activities undertaken to adapt to a stressor that has already taken place (e.g., Lazarus \& Folkman, 1984). We argue that proactive coping and reactive coping incorporate the same strategies, such as making plans and finding social support, in order to deal with the stressor; the terms 'proactive' and 'reactive' only refer to the timing of that particular stressor (for similar reasoning, see Aldwin, 1999).

According to our conception of proactive coping, future stressors are by definition only potentially threatening and, as such, they remain more or less ambiguous. Consequently, they must be monitored over time to determine whether the potential threats develop into real problems (Aspinwall, 1997). Not surprisingly, Aspinwall and Taylor (1997) regard using avoidant proactive coping to deal with a future, potentially controllable stressor as an ineffective strategy: if an individual disengages from a possible threat, he or she is not able to take appropriate measures to offset the stressful event at the right moment. Active, problem-focused and support-seeking strategies are necessary to deal effectively with a future threat and its consequences. Moreover, problem-focused proactive coping is likely to provide the individual with helpful information about the development of the stressor as well as the results of initial coping attempts to alter the course of the stressor (Aspinwall \& Taylor, 1997).

These proactive coping strategies have scarcely been examined empirically. The aim of the present study, therefore, is to examine them in detail and also to investigate the factors that contribute to proactive coping. More specifically, we will examine to what extent situational factors and personal characteristics influence the use of proactive coping. Since middle-aged and older adults are likely to deal with many potential stressful changes due to aging, we suggest that this age group is an interesting one in which to examine proactive coping. Particularly within this research group individuals have to deal with an increasingly unfavourable scenario in which the balance shifts towards fewer gains and a greater number of threats (e.g., Baltes \& Baltes, 1990).

An important question, and one which has been studied in the field of (reactive) coping, is "to what extent proactive coping varies across different situations? and to what extent it is predicted by personal characteristics?', Researchers have demonstrated that the range of coping behaviour is limited in individuals and that people often have certain coping preferences (e.g., Endler \& Parker, 1990). Moderate to fairly strong associations have been found between coping styles and coping responses to specific situations (Bouchard, Guillemette, \& Landry-Le' ger, 2004; Buchwald, 2003; Carver \& Scheier, 1994; Endler, Kantor, \& Parker, 1994). Moreover, previous coping responses are a strong predictor of how an individual will cope with a new situation (Terry, 1994), although this is mainly true when the situation is similar to the one already experienced (Patterson et al., 1990). Although it is likely that there is some stability in proactive coping responses, this remains a rather limited description of the concept.

Research has also yielded results in favour of the transactional perspective originally proposed by Lazarus and Folkman (1984), who stated that the individual and the environment interact in creating coping responses. Although researchers have found that dispositional and situational coping generally share $20-30 \%$ of variance, this leaves a great amount of unexplained variance (Bouchard et al., 2004). Combining trait and state approaches of coping may provide a more comprehensive understanding of its process (Moos \& Holahan, 2003). While personal coping resources do affect coping behaviour (e.g., Terry, 1991), previous research has also demonstrated that people are not consistent in their coping responses across situations and that coping strategies also vary as a function of specific situational characteristics (De Ridder \& Kerssens, 2003; Holahan \& Moos, 1987; Kaissidis-Rodafinos \& Anshel, 2000; Mattlin, Wethington, \& Kessler, 1990; McCrae, 1984; Stewart \& Schwarzer, 1996; Terry, 1994), such as type of stressor, appraised threat and appraised control, and several objective features of the situation. De Ridder and Kerssens (2003) even found that people vary more in their coping responses across situations than they do in relation to other individuals responding to the same situation. Moreover, it has been argued that people who are able to adjust their coping responses to the 
Ouwehand, C., Ridder, D.T.D. de, Bensing, J.M.

Situational aspects are more important in shaping proactive coping behaviour than

individual characteristics: a vignette study among adults preparing for ageing.

Psychology and Health: 21, 2006, nr. 6, p. 809-825

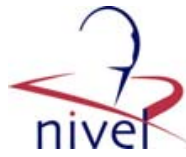

demands of the situation, that is those who have a certain amount of coping flexibility, may be able to adapt more effectively to stressors (Cheng, 2001).

In order to examine proactive coping in different situations, we conducted a field experiment using vignettes. Research has shown that vignettes are a valid method for studying coping responses to stressful situations so long as certain conditions are met, such as participants having the opportunity to process the information adequately in a quiet environment without distraction (Stolte, 1994).

Furthermore, Krohne and Egloff (1999) have proposed that vignettes are an appropriate method for triggering coping responses when (1) the situations described in the vignettes are imaginable and (2) the vignettes cause a certain amount of threat (De Ridder, \& Kerssens, 2003). One of our previous studies indeed demonstrated that at least a slight feeling of threat must be experienced, as this focuses attention on the future stressor and encourages engagement in proactive coping (Ouwehand, De Ridder $\&$ Bensing, 2001). An advantage of using vignettes is that all individuals have to respond to the same types of stressors, which makes it easier to control the characteristics of the stressor and to compare proactive coping between individuals.

A focus group study of 47 persons aged between 50 and 70 years demonstrated that being healthy, having good social relationships and having sufficient financial assets were the most important issues for this age group (Ouwehand et al., 2001). A decline in these resources was experienced as a serious threat to their personal goals. For the purpose of the present study, three vignettes were developed each describing a situation in which a person faces a probable, but uncertain decrease in one of the resources, in line with Aspinwall and Taylor's (1997) definition of proactive coping.

Several personal variables have been assumed to facilitate proactive coping with potential decreases in resources. A future temporal orientation might be considered as one of the factors positively influencing the proactive coping process, as it may assist in the detection of a future stressor (Aspinwall \& Taylor, 1997) and engagement in preventive behaviour (Rothspan \& Read, 1996). Selfefficacy may be another important proactive coping resource, because previous research has found that individuals high in self-efficacy have lower stress appraisals ( Jerusalem, 1993) and use more problem-focused coping strategies (MacNair \& Elliott, 1992). Perceiving potential threats as less stressful encourages a person to use proactive coping, as people who think that they are at lower risk pay more attention to a future threat (Aspinwall \& Brunhart, 1996). In addition, an individual with high self-efficacy believes that he or she is able to deal successfully with challenging environmental demands by taking effective, problem-solving measures (Bandura, 1997; Schwarzer, 1992). The proactive coping process may also be facilitated by a goal orientation, since individuals who reflect on their future plans and who tend to set both short-term and long-term goals may be better able to recognize potential threats to these goals. Finally, it is expected that individuals with a tendency to use proactive coping will be more inclined to employ such strategies when confronted with a potential stressor. Although there is discussion on the question of whether coping styles influence coping behaviour and even whether coping styles exists at all (see e.g., Carver \& Scheier, 1994; Schwartz, Neale, Marco, Shiffman, \& Stone, 1999), it is still interesting to examine the possibility that a proactive coping style influences actual proactive coping behaviour.

Although stable personal factors may also be important, we assume that a potential decline in certain resources more than others is a greater trigger for proactive coping. We hypothesize that proactive coping varies between situations and that several characteristics of the stressor may cause this variability. More specifically, in this study we will examine to what extent type of stressor, appraised threat to personal goals and appraised control over the situation are important predictors of proactive coping. Regarding type of stressor, we predict that potentially decreasing health will provoke more proactive coping than threats to social relationships and financial resources. Health might be considered one of the core resources necessary for well-being and attainment of personal goals and some researchers have argued that it may be difficult for people to accommodate health-related goals (Brandtstädter \& Rothermund, 2002). We expect people to be sensitive to even minor threats to their health and to make more efforts to prevent a decline in this resource.

In addition, we hypothesize that a higher appraised threat to personal goals and a higher appraised control over the situation will contribute to proactive coping strategies. As has already been described previously, a situation needs to pose a certain amount of threat to personal goals in order for the stressor to be perceived as a problem and for people to be motivated to act. On the contrary, too great a 
Ouwehand, C., Ridder, D.T.D. de, Bensing, J.M.

Situational aspects are more important in shaping proactive coping behaviour than

individual characteristics: a vignette study among adults preparing for ageing.

Psychology and Health: 21, 2006, nr. 6, p. 809-825

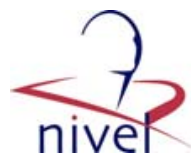

threat will probably lead to disengagement from the stressor instead of active coping. Finally, research has shown that when individuals think they can manage or alter a situation, they cope more successfully (e.g., Aspinwall \& Taylor, 1992). The feeling that one has no control over a situation may lead to acceptance of the situation, while higher controllability may lead to more proactive coping.

\section{METHOD}

\section{Participants and procedure}

The present study is a follow-up study of a larger survey study $(N=397)$ examining proactive coping employed by normal, healthy middle-aged and older adults. It consisted of 123 persons $(63$ men and 60 women) aged between 50 and 70 years $(M=61.8 ; \mathrm{SD}=5.0)$ who were willing to participate in an interview. Of this sample, $72 \%$ were married, $7 \%$ were divorced and $11 \%$ were widowed. Regarding educational level, $24 \%$ had a college or university degree and $48 \%$ had obtained a high school diploma. In relation to employment, $28 \%$ of the participants had a paid job, $38 \%$ were retired, while $24 \%$ reported housekeeping as their main activity. No significant differences were found between the original sample and the present sample with respect to age and gender, although participants in the current study had a slightly higher level of education $(t=3.0, p<0.001)$.

Participants were interviewed at the university or at home when there were mobility problems. After an appointment had been made by telephone, they received a short questionnaire which they filled in at home and which they brought to the interview. The questionnaire assessed several personal factors. During the interview, the participants were asked to respond to three vignettes in order to measure proactive coping in different situations.

\section{Situational characteristics}

Three vignettes were developed by the authors and slightly modified following a pilot study. Each vignette described a potential loss of one of the following resources: health (situation 1), social relationships (situation 2) and personal finance (situation 3). A full description of vignettes can be found in the appendix. Care was taken to ensure that the three vignettes were sufficiently imaginable and that they involved a certain amount of threat. In addition, the participants were interviewed in a quiet room in order to allow them to concentrate and process the information effectively (Stolte, 1994).

Besides manipulating Type of Stressor, two other situational features were assessed in order to examine whether they predict proactive coping. First, Appraised Threat to Personal Goals was measured by asking participants in relation to each vignette "To what extent would this situation threaten the things you would like to do or achieve?" (4-point scale ranging from 1=not at all to $4=v e r y$ much). Second, Appraised Control over Situation was measured with the question 'Do you feel that you would be able to influence this situation?'. Again, participants answered on a 4-point scale and for each vignette separately.

\section{Proactive coping}

Aspinwall and Taylor (1997) argued that proactive coping primarily consists of various problemfocused coping strategies, such as planning, seeking instrumental support and actively taking measures to prevent a potential stressor instead of denying the problem or disengaging from it. These elements were measured with items from four COPE scales (Carver, Scheier, \& Weintraub, 1989) written on small cards. As the COPE was originally developed to measure coping reactions to a stressful event that has already taken place, some of the items were changed slightly in order to make them more appropriate for a proactive coping context. For example, the item "I take direct action to get around the problem" of the subscale Active Coping was altered into "I take direct action to prevent this potential problem". After participants had been asked to read the vignettes carefully and to imagine the situation described as well as they could, they indicated to what extent they would respond to the potential stressor as written on the card (4-point Likert scale, ranging from certainly no to certainly yes). Due to tiredness, two participants did not complete questions related to the third vignette.

We included the following four subscales that each consisted of four items. Active Coping (Cronbach's $\alpha=0.71,0.80$ and 0.73 for Vignette 1, 2 and 3 respectively) involves actions to prevent the stressor or its consequences occurring while Planning ( $\alpha^{\prime} s=0.74,0.83$ and 0.87$)$ represents thinking 
Ouwehand, C., Ridder, D.T.D. de, Bensing, J.M.

Situational aspects are more important in shaping proactive coping behaviour than

individual characteristics: a vignette study among adults preparing for ageing.

Psychology and Health: 21, 2006, nr. 6, p. 809-825

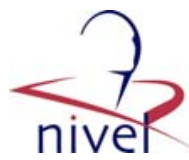

about how to handle the stressor (Carver et al., 1989). Suppression of Competing Activities ( $\alpha$ 's $=0.65$, 0.74 and 0.73 ) means putting other activities aside in order to concentrate on the problem and the fourth subscale, Seeking Social Support for Instrumental Reasons ( $\alpha$ 's $=0.84,0.89$ and 0.91 ) involves seeking information or advice (Carver et al., 1989). It is generally known that these subscales tend to correlate highly with each other. In this particular study, the inter-correlations ranged from 0.31 to 0.70 for all three situations.

\section{Personal factors}

Besides age, gender and education, four other personal characteristics, namely dispositional proactive coping style, self-efficacy, future temporal orientation and goal orientation were included in this study. Proactive Coping Style was measured with the Preventive Coping Subscale of the Proactive Coping Inventory (Greenglass, Schwarzer, \& Taubert, 1999), which consisted of ten items on a 4-point Likert scale (ranging from $1=$ not at all applicable to me to $4=$ completely applicable to me). We argue that this particular subscale is a proper operationalization of what dispositional proactive coping style entails, namely the tendency to prevent potential stressors before they fully develop. Its items represent a fairly stable characteristic of generally anticipating future stressors. Sample items include "I prepare for adverse events" and "Before disaster strikes I am well-prepared for its consequences". Greenglass et al. (1999) have reported that the subscale has good internal consistency and that it shows sufficient discriminant validity as well as adequate construct validity. In the present study, Cronbach's alpha was 0.84 .

We used the Generalized Self-efficacy scale (Schwarzer, 1992) to assess Self-efficacy, which may be defined as the belief that one is capable of coping with difficulties and that one's own actions are responsible for success. The scale consists of ten items on a 4-point Likert scale $(\alpha=0.89)$. Sample items are "I can usually handle whatever comes my way" and "I can always manage to solve difficult problems if I try hard enough".

In addition, Future Temporal Orientation was measured with the Future subscale $(\alpha=0.61)$ of the Temporal Orientation scale ( Jones, Banicky, Lasane, \& Pomare, 2005). Participants had to answer five items on a 5-point Likert scale. Sample items are "I take care of what needs to be done before having fun" and "I am able to resist temptation when there is work to be done". A high score means that a person is a planner, is concerned with the future and is able to imagine future possibilities.

Finally, participants completed the Goal Orientation scale $(\alpha=0.73)$ developed by Malouff and colleagues (1990) in order to assess Goal Orientation, that is the degree to which an individual has a tendency to set short-term as well as long-term goals and make plans to achieve these goals. It consisted of 15 items on a 5-point Likert scale (ranging from strongly disagree to strongly agree) and sample items include "I am goal-oriented" and "I spend a substantial amount of time planning how to reach my goals".

Table I shows the zero-order correlations between the variables described earlier. Although proactive coping style, self-efficacy, future temporal orientation and goal orientation were positively and significantly associated, the scales remain meaningfully independent of one another. Therefore, all personal variables were included in the analyses.

\section{[ TABLE 1 ]}

\section{Statistics}

In order to examine to what extent situational characteristics and personal factors predicted the variance in proactive coping, multilevel analysis was conducted using MLwiN 1.1 (Rasbash et al., 2002), since multilevel analysis is recommended for nested data (Hox, 2002). Such an analysis takes into account that proactive coping responses to the three situations are correlated within the same individual. Moreover, it is able to handle incomplete cases if participants did not respond to all the vignettes (Hox, 2002).

In our study, we had two levels of nesting: situations (level 1) were nested within adults (level 2). We started our analyses with an intercept-only model that divides the variance of proactive coping into two independent components: situational variance and individual variance. This allows for calculating the interclass correlation $\rho$ that, in this study, indicates the proportion of the variance explained by the variance between individuals. In the second step, the fixed variable Type of Stressor, which is a 
Ouwehand, C., Ridder, D.T.D. de, Bensing, J.M.

Situational aspects are more important in shaping proactive coping behaviour than

individual characteristics: a vignette study among adults preparing for ageing.

Psychology and Health: 21, 2006, nr. 6, p. 809-825

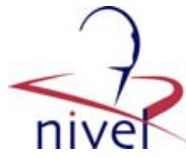

categorical variable, was added. Consequently, dummy coding was used with 'health' as the reference category. Next, we included the fixed variables Appraised Threat and Appraised Control measured at the first level in order to test whether this may further explain the situational variance. In the fourth model, we added the personal factors. A final step in the multilevel analyses was to test whether there were significant random slope variations for the variables assessed at the lowest level (i.e., type of stressor, appraised threat and appraised control). In our study, differences in the slope coefficient for e.g., type of stressor would indicate that the relationship between type of stressor and the use of proactive coping strategies is not the same for all individuals.

Variables were centred before they were entered in the multilevel model. Multilevel analyses were conducted for each proactive coping strategy separately, which resulted in four analyses. Assumptions of linearity, normality and homoscedasticity on both levels were checked and were found to be in order. Finally, we used the Snijders and Bosker (1994) correction in order to calculate the explained variances at the different levels (see Hox, 2002; Snijders \& Bosker, 1994).

\section{RESULTS}

Analyses demonstrated that most participants could imagine the situations well $(94,81$ and $94 \%$ for health, social relationships and finance respectively). As far as the health vignette was concerned, $70 \%$ of the participants indicated that they had already experienced the same or a comparable situation. Fewer individuals had encountered a similar or comparable situation to the ones described in the social vignette $(51 \%)$ or the financial vignette $(34 \%)$ at the time of interviewing. It is worth noting that the level of any of the four proactive coping strategies employed did not depend on whether the participants had already experienced the same or a comparable situation ( $p$ 's ranged from 0.10 to 0.61 ) or whether they could imagine the situation well ( $p$ 's ranged from 0.17 to 0.77 ). Neither did perceived threat and perceived control depend on these two variables ( $p$ 's were between 0.10 and 0.84 ) except for the social situation. People who had experienced a similar situation to the one described in the social contacts vignette perceived more control over the situation than people who did not $(F(3,116)=7.03, p<0.001)$. In addition, individuals who did not encounter such an event themselves, but had watched another person undergoing a similar experience undertook more active coping strategies $(F(3,116)=7.92, p<0.001)$, planning strategies $(F(3,116)=9.92, p<0.001)$ and suppression of competing activities strategies $(F(3,116)=6.99, p<0.001)$ than persons who had already experienced it themselves.

Table II shows basic results for the four proactive coping strategies used in the three situations as well as the proactive coping resources that may differ from individual to individual. Firstly, it is clear that on an average all situations were appraised as a medium threat to personal goals, but that the potential decrease in social contacts was perceived as least threatening. In addition, this situation was also regarded as most controllable. Secondly, active coping and planning were the strategies employed most often whereas suppression of competing activities and seeking social support for instrumental reasons were employed the least. On average, proactive coping strategies were most often used in the health situation. GLM repeated measures analysis showed that the amount of strategies employed in the three situations differed significantly as well as the degree to which the situations were appraised as threatening and controllable (see Table II).

\section{[ TABLE 2 ]}

In order to examine to what extent situational and personal characteristics predict proactive coping, we first separated the situational variance from the individual variance by testing the intercept-only model. Intraclass correlations can be calculated by dividing the individual variance by the total variance $\left(\rho=\sigma_{\text {between }}^{2}=\sigma_{\text {between }}^{2}+\sigma_{\text {within }}^{2}\right.$ ). This resulted in the following intraclass correlations: 0.34 (active coping), 0.40 (planning), 0.41 (suppression of competing activities) and 0.48 (seeking instrumental support). This means that the variance of proactive coping across situations within the same person is slightly greater than the variance between persons, in other words, proactive coping varies more within the same person than from person to person. For active coping situational factors are most relevant, whereas for seeking instrumental support situational characteristics and personal factors are approximately equally relevant. 
Ouwehand, C., Ridder, D.T.D. de, Bensing, J.M.

Situational aspects are more important in shaping proactive coping behaviour than

individual characteristics: a vignette study among adults preparing for ageing.

Psychology and Health: 21, 2006, nr. 6, p. 809-825

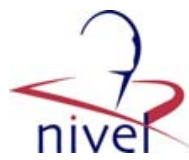

The next step was to examine which situational and personal features may explain the different variances. Table III shows that type of stressor is a significant predictor of proactive coping. As expected, the potential decline in health evokes more proactive coping strategies than the possible decrease in social contacts or financial resources, with the exception of planning and suppression of competing activities. When confronted with the potential financial stressor, people do not plan less than when their health might be at risk. Nevertheless, the decrease in deviance between the interceptonly model and the model including both dummies was significant $(\Delta$ deviance $=11.97, p<0.01)$. The deviance indicates how well the model fits the data; a model with a significantly lower deviance (in this case, the model including the dummies) fits better than a model with a higher deviance (in this case, the intercept-only model) (Hox, 2002). In addition, the financial stressor leads to more suppression of competing activities than the health stressor while the social stressor does not contribute to suppression. However, there was a significant decrease in deviance ( $\Delta$ deviance $=12.77, p$ $<0.01$ ). Thus, it was concluded that for all four proactive coping strategies type of stressor is a relevant predictor. Furthermore, the results showed that greater appraised threat to personal goals and greater appraised control over the situation lead to increased use of all four proactive coping strategies.

\section{[ TABLE 3 ]}

With respect to the role of personal factors, it appeared that sociodemographic variables, such as age, gender and education, did not contribute significantly to proactive coping although education showed a positive trend for support seeking. Proactive coping style and self-efficacy proved not to be relevant. With respect to the remaining personal variables, mixed results were found. Having a future temporal orientation was important for all strategies, with the exception of instrumental support seeking whereas being goal-oriented only predicted planning.

Table II shows that the four fixed situational factors explain $8-11 \%$ of the variance at the situational level while the personal characteristics, namely socioeconomic variables, proactive coping resources as well as proactive coping style, explain more variance (11-31\%) at the personal level.

Finally, significant random slope variation was found for the variable type of stressor, but not for appraised threat and appraised control. This means that the regression slope for type of stressor varies from person to person, in other words, whether a situation provokes more proactive coping than another situation depends on the individual. Interestingly, the covariances between the slopes showed that when an individual reports high proactive coping for the health vignette, it is likely that he or she will report less proactive coping for the social vignette or financial vignette. However, when proactive coping was already low in the health situation, it remained low in the other two situations.

\section{DISCUSSION}

The present study examined the extent to which situational factors and personal characteristics contributed to proactive coping, which is a concept that has been rarely researched empirically, but which is nonetheless promising. We found that proactive coping strategies varied greatly within the same individual across different situations. Proactive coping variability across situations was even greater than the variability between individuals. At least three factors, namely type of stressor and appraisals of threat and control, explained variance on the situational level. The influence of subjective appraisals is a well-established research result and often regarded as the most important factor in shaping coping responses (Lazarus \& Folkman, 1984). When a situation is appraised as a higher threat to personal goals and as more controllable, a person uses more proactive coping strategies. In addition, we showed that the more objective feature 'type of stressor' shapes proactive coping. As predicted, the potential health threat provoked more proactive coping than the future threat to social relationships and financial resources, with the exception of suppression of competing activities. This strategy is more often employed when confronted with a potential decline in financial resources.

The results also demonstrated that the relationship between type of stressor and proactive coping varies from person to person; for example, some people used more proactive coping in the health situation than in the financial situation whereas for other individuals the pattern was just the opposite. It is interesting that we found this effect while researching proactive coping in only three different situations, since it is generally recommended that at least 100 groups be measured at the second level 
Ouwehand, C., Ridder, D.T.D. de, Bensing, J.M.

Situational aspects are more important in shaping proactive coping behaviour than

individual characteristics: a vignette study among adults preparing for ageing.

Psychology and Health: 21, 2006, nr. 6, p. 809-825

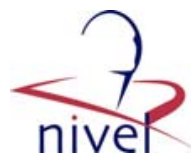

(in this study: adults) with each at least 10 units (in this study: vignettes) (Hox, 2002). It is probable that the effect will be even stronger when presenting more situations to individuals. Nevertheless, future research may concentrate on examining proactive coping in a larger sample measuring responses to more situations in order to gain more statistical power with which to study which personal characteristics contribute to the random slope variation. It would be interesting to examine whether the individual differences in responses to the situations are mainly due to type of stressor or also due to the possibility that one stressor is appraised in a different manner than another.

Furthermore, it would also be interesting for future research to vary the situations in relation to factors other than type of stressor, such as by varying the degree of ambiguity of the situation and the time until the potential stressor is likely to strike.

The interindividual differences in proactive coping were quite well explained by the combination of personal factors we included in this study. As was hypothesized, having a future temporal orientation had a positive impact on all four proactive coping strategies except on instrumental support seeking. However, none of the other factors appeared to have a major influence. A possible explanation may be that the middle-aged and older adults in our study had on average a lot of coping resources, which may have made them a rather homogeneous sample. Other personal features not included in this study may also explain additional variance. Instrumental support seeking, which was not affected by any of the individual characteristics, may depend on factors such as differences in network size and need for social contacts.

The finding that dispositional proactive coping style did not affect proactive coping is consistent with some of the literature (Carver \& Scheier, 1994; Schwartz et al., 1999). On the basis of their study, Schwartz and colleagues (1999) suggested that a self-report coping questionnaire might be an inaccurate assessment of the dispositional component of coping. They propose that an aggregation of an individual's responses across multiple, different situations may be a better way to obtain a measure of trait coping.

A potential limitation of this study may be its design. The potential artificiality of vignettes may weaken the external validity of the results (De Ridder \& Kerssens, 2003). However, results showed that most people were familiar with the situations described in the vignettes. Moreover, a certain amount of people reported that they had already experienced the same or a comparable situation, particularly in the case of the health vignette. This may have led to even more accurate responses of proactive coping, because they could imagine the situation well.

In conclusion, examining both the situational and individual influences provides a more complete picture of proactive coping behaviour. Using vignettes may be a useful way to research such factors. However, measuring responses to potentially stressful situations remains an interesting challenge for future research. Several researchers have suggested that problems arise when assessing (proactive) coping through the use of checklists with prepared response items. It could be argued that the extent to which individuals are able to correctly report their coping efforts is questionable (Schwartz et al., 1999), whilst other problems, such as socially desirable answering, may also bias the data (Coyne \& Gottlieb, 1996). Another important point is that proactive coping is regarded as a process that incorporates many different elements and that these may not be captured in one single measurement, particularly not using a checklist. A potential alternative for using a standardized checklist of coping responses, such as the COPE, is a semi-structured interview administered by carefully selected and trained interviewers. An advantage of this method is that it assesses individual coping responses and is able to detect changes and patterns in these responses (Coyne \& Gottlieb, 1996). A disadvantage, however, is the time and resource consuming nature of the method. Moreover, it may be more difficult to compare the obtained results across individuals with generally used statistical tests. Future research might consider examining different aspects of the proactive coping process one at a time while using other instruments than self-report measures.

\section{ACKNOWLEDGEMENTS}

The authors would like to thank Bianca Hesdal, Klaske van Loon, Anoek Spitsbaard and Marie-Janne van Toorn for assisting in data collection. They would also like to express their thanks to Dr Mirjam Moerbeek from the Department of Methodology and Statistics of the Utrecht University for her help with the multilevel analyses. 
Ouwehand, C., Ridder, D.T.D. de, Bensing, J.M

Situational aspects are more important in shaping proactive coping behaviour than

individual characteristics: a vignette study among adults preparing for ageing

Psychology and Health: 21, 2006, nr. 6, p. 809-825

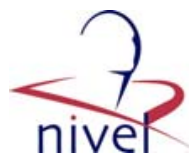

\section{REFERENCES}

Aldwin, C. M. (1999). Stress, coping, and development: An integrative approach. New York: Guilford.

Aspinwall, L. G. (1997). Where planning meets coping: Proactive coping and the detection and management of potential stressors. In S. L. Friedman \& E. K. Scholnick (Eds), The developmental psychology of planning: Why, how, and when do we plan? (pp. 285-320). London: Lawrence Erlbaum Associates, Publishers.

Aspinwall, L. G., \& Taylor, S. E. (1992). Modeling cognitive adaptation: A longitudinal investigation of the impact of individual differences and coping on college adjustment and performance. Journal of Personality and Social Psychology, 63, 989-1003.

Aspinwall, L. G., \& Brunhart, S. M. (1996). Distinguishing optimism from denial: Optimistic beliefs predict attention to health threats. Personality and Social Psychology Bulletin, 22, 993-1003.

Aspinwall, L. G., \& Taylor, S. E. (1997). A stitch in time: Self-regulation and proactive coping. Psychological Bulletin, 121, 417-436.

Baltes, P. B., \& Baltes, M. M. (1990). Psychological perspectives on successful aging: The model of selective optimization with compensation. In P. B. Baltes \& M. M. Baltes (Eds), Successful aging: Perspectives from the behavioral sciences (pp. 1-34). New York: Cambridge University Press.

Bandura, A. (1997). Self-efficacy: The exercise of control. New York: Freeman.

Bouchard, G., Guillemette, A, \& Landry-Le'ger, N. (2004). Situational and dispositional coping: An examination of their relation to personality, cognitive appraisals, and psychological distress. European Journal of Personality, 18, 221-238.

Brandtstädter, J., \& Rothermund, K. (2002). The life-course dynamics of goal pursuit and goal adjustment: A two-process framework. Developmental Review, 22, 117-150.

Buchwald, P. (2003). The relationship of individual and communal state-trait coping and interpersonal resources as trust, empathy and responsibility. Anxiety, Stress, and Coping, 16, 307-320.

Carver, C. S., \& Scheier, M. F. (1994). Situational coping and coping dispositions in a stressful transaction. Journal of Personality and Social Psychology, 66, 184-195.

Carver, C. S., Scheier, M. F., \& Weintraub, J. K. (1989). Assessing coping strategies: A theoretically based approach. Journal of Personality and Social Psychology, 56, 267-283.

Cheng, C. (2001). Assessing coping flexibility in real-life and laboratory setting: A multimethod approach. Journal of Personality and Social Psychology, 80, 814-833.

Coyne, J. C., \& Gottlieb, B. H. (1996). The mismeasure of coping by checklist. Journal of Personality, 64, 959-991.

De Ridder, D. T. D., \& Kerssens, J. (2003). Owing to the force of circumstances? The impact of situational features and personal characteristics on coping patterns across situations. Psychology and Health, 18, 217-236.

Endler, N. S., \& Parker, J. D. A. (1990). Multidimensional assessment of coping: A critical evaluation. Journal of Personality and Social Psychology, 58, 844-854.

Endler, N. S., Kantor, L., \& Parker, J. D. A. (1994). State-trait coping, state-trait anxiety and academic performance. Personality and Individual Differences, 16, 663-670.

Greenglass, E. R. (2002). Proactive coping and quality of life management. In E. Frydenberg (Ed.), Beyond coping: Meeting goals, visions, and challenges (pp. 37-62). London: Oxford University Press.

Greenglass, E. R., Schwarzer, R., \& Taubert, S. (1999). The Proactive Coping Inventory (PCI): A multidimensional research instrument. [On-line] Available: http://userpage.fuberlin.de/ health/procoping.htm

Holahan, C. J., \& Moos, R. H. (1987). Personal and contextual determinants of coping strategies. Journal of Personality and Social Psychology, 52, 946-955.

Hox, J. J. (2002). Multilevel analysis. Techniques and applications. London: Lawrence Erlbaum Associates, Publishers.

Jerusalem, M. (1993). Personal resources, environmental constraints, and adaptational processes:

The predictive power of a theoretical stress model. Personality and Individual Differences, 14, 15-24.

Jones, J. M., Banicky, L., Lasane, T. P., \& Pomare, M. (2005). A temporal orientation scale: Focusing attention on past, present and future. Unpublished manuscript, University of Delaware, USA.

Kaissidis-Rodafinos, A., \& Anshel, M. H. (2000). Psychological predictors of coping responses among Greek basketball referees. The Journal of Social Psychology, 140, 329-344.

Krohne, H. W., \& Egloff, B. (1999). Vigilant and avoidant coping: Theory and measurement. In C. D. Spielberger \& I. G. Sarason (Eds), Stress and emotion. Washington, DC: Taylor \& Francis.

Lazarus, R. S., \& Folkman, S. (1984). Stress, appraisal and coping. New York: Springer Publishing Company, Inc. 
Ouwehand, C., Ridder, D.T.D. de, Bensing, J.M.

Situational aspects are more important in shaping proactive coping behaviour than

individual characteristics: a vignette study among adults preparing for ageing.

Psychology and Health: 21, 2006, nr. 6, p. 809-825

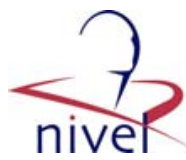

MacNair, R. R., \& Elliott, T. R. (1992). Self-perceived problem solving ability, stress appraisal, and coping over time. Journal of Research in Personality, 26, 150-164.

Malouff, J., Schutte, N., Bauer, M., Mantelli, D., Pierce, B., Cortova, G., \& Reed, E. (1990). Development and evaluation of a measure of the tendency to be goal oriented. Personality and Individual Differences, 11, 1191-1200.

Mattlin, J. A., Wethington, E., \& Kessler, R. C. (1990). Situational determinants of coping and coping effectiveness. Journal of Health and Social Behavior, 31, 103-122.

McCrae, R. R. (1984). Situational determinants of coping responses: Loss, threat, and challenge. Journal of Personality and Social Psychology, 46, 919-928.

Moos, R. H., \& Holahan, C. J. (2003). Dispositional and contextual perspectives on coping: Toward an integrative framework. Journal of Clinical Psychology, 59, 1387-1403.

Ouwehand, C., De Ridder, D. T. D., \& Bensing, J. M. (2001). Proactive adaptation to ageing: An exploratory focus group study. Unpublished manuscript, Utrecht University, Utrecht, The Netherlands.

Patterson, T. L., Smith, L. W., Grant, I., Clopton, P., Josepho, S., \& Yager, J. (1990). Internal vs. external determinants of coping responses to stressful life-events in the elderly. British Journal of Medical Psychology, 63, 149-160.

Rasbash, J., Browne, W., Goldstein, H., Yang, M., Plewis, I., Healy, M., et al. (2002). A user's guide to MlwiN. London: Institute of Education, University of London.

Rothspan, S., \& Read, S. J. (1996). Present versus future time perspective and HIV risk among heterosexual college students. Health Psychology, 15, 131-134.

Schwartz, J. E., Neale, J., Marco, C., Shiffman, S. S., \& Stone, A.A. (1999). Does trait coping exist? A momentary assessment approach to the evaluation of traits. Journal of Personality and Social Psychology, 77, 360-369.

Schwarzer, R. (1992). Self-efficacy: Thought control of action. Washington, DC: Hemisphere.

Schwarzer, R. (2001). Stress, resources, and proactive coping. Applied Psychology: An International Review, 50, 400-407.

Schwarzer, R., \& Taubert, S. (2002). Tenacious goal pursuits and striving toward personal growth: Proactive coping. In E. Frydenberg (Ed.), Beyond coping: Meeting goals, visions, and challenges (pp. 19-35). London: Oxford University Press.

Snijders, T. A. B., \& Bosker, R. J. (1994). Modeled variance in two-level models. Sociological Methods \& Research, 22, 342-363.

Stewart, S. M., \& Schwarzer, R. (1996). Stability of coping in Hong Kong medical students: A longitudinal study. Personality and Individual Differences, 20, 245-255.

Stolte, J. F. (1994). The context of satisficing in vignette research. The Journal of Social Psychology, 134, 727-733.

Terry, D. J. (1991). Coping resources and situational appraisals as predictors of coping behavior. Personality and Individual Differences, 12, 1031-1047.

Terry, D. J. (1994). Determinants of coping: The role of stable and situational factors. Journal of Personality and Social Psychology, 66, 895-910.

\section{APPENDIX}

The vignettes printed here represent the male version; for the female version ' $\mathrm{Mr}$ ' was replaced by 'Mrs', 'man' by 'woman', and 'he' was replaced by 'she'.

\section{Vignette 1 (Health)}

Imagine Mr Hendricks' situation. Mr Hendricks is an active man of your age. Over the last year he has noticed that he is getting less supple. He is also suffering from some so-called "old people's complaints", such as finding it more difficult to rise from a chair. Nevertheless, Mr Hendricks can do everything he used to do, but he does it less easily and often less energetically. These days, he sometimes thinks about the possibility that this situation will not improve in the short term. It is even possible that it will get worse in the future.

\section{Vignette 2 (Social relationships)}

Imagine Mr Miller's situation. Mr Miller is an active man of your age. He is satisfied with the social relationships he has, especially now that he has more time to see and talk to his friends and family. Nevertheless, he has noticed that everyone's life is changing. Most people are about to retire or have already retired and the children have grown up and started their own lives. So, Mr Miller sometimes 
Ouwehand, C., Ridder, D.T.D. de, Bensing, J.M.

Situational aspects are more important in shaping proactive coping behaviour than

individual characteristics: a vignette study among adults preparing for ageing.

Psychology and Health: 21, 2006, nr. 6, p. 809-825

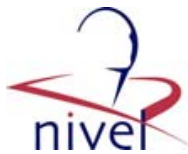

thinks about the possibility that he and the people around him may grow apart, as everyone goes his or her own way and becomes occupied with different things. Next thing you know, they will only be seeing each other at birthday parties!

\section{Vignette 3 (Personal finance)}

Imagine Mr Brook's situation. Mr Brook is an energetic man of your age. He believes he has enough money to get by. He also believes he has enough money to engage in enjoyable activities and to buy nice things. Now he is getting older, Mr Brook sometimes thinks about the possibility that at some point in the future he may have less money to spend each month. Although he will manage, he will not be able to do so much or buy so many nice things anymore.

\section{TABLES}

Table I. Zero-order correlations between the personal factors $(N=123)$.

\begin{tabular}{lccccccc}
\hline & 1 & 2 & 3 & 4 & 5 & 6 \\
\hline 1. Age & - & & & & & \\
2. Gender & a & 0.01 & - & & & & \\
3. Education & -0.10 & $0.45^{\star \star}$ & - & & & \\
4. Proactive coping style & -0.01 & 0.10 & $0.24^{\star \star}$ & - & & \\
5. Self-efficacy & -0.12 & 0.13 & -0.09 & $0.31^{\star \star}$ & - & \\
6. Future temporal orientation & -0.17 & 0.02 & -0.06 & $0.36^{\star \star}$ & $0.22^{\star}$ & - & \\
7. Goal orientation & $-0.22^{\star}$ & 0.12 & 0.11 & $0.39^{\star \star}$ & 0.14 & $0.46^{\star \star}$ & - \\
\hline
\end{tabular}

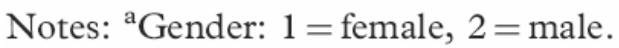

${ }^{\star} p<0.05 ;{ }^{\star \star} p<0.01$.

Table II. Proactive coping strategies and proactive coping resources (Mean (SD)).

\begin{tabular}{lrccccc}
\hline & Range & Total & $\begin{array}{c}\text { Health } \\
\text { vignette }\end{array}$ & $\begin{array}{c}\text { Social } \\
\text { vignette }\end{array}$ & $\begin{array}{c}\text { Finance } \\
\text { vignette }\end{array}$ & $F(2,238)^{1}$ \\
\hline Active coping & $4-16$ & - & $12.3(2.7)_{\mathrm{a}}$ & $11.3(3.3)_{\mathrm{b}}$ & $11.7(3.0)_{\mathrm{a}, \mathrm{b}}$ & $5.78^{\star \star}$ \\
Planning & $4-16$ & - & $11.8(3.0)_{\mathrm{a}}$ & $10.9(3.4)_{\mathrm{b}}$ & $11.8(3.4)_{\mathrm{a}}$ & $7.17^{\star \star}$ \\
Suppression of activities & $4-16$ & - & $9.5(2.8)_{\mathrm{a}, \mathrm{b}}$ & $8.9(3.1)_{\mathrm{a}}$ & $10.1(3.0)_{\mathrm{b}}$ & $8.01^{\star \star}$ \\
$\begin{array}{l}\text { Seeking instrumental } \\
\quad \text { support }\end{array}$ & $4-16$ & - & $11.2(3.7)_{\mathrm{a}}$ & $9.6(3.9)_{\mathrm{b}, \mathrm{c}}$ & $9.9(4.0)_{\mathrm{c}, \mathrm{b}}$ & $10.38^{\star \star}$ \\
$\begin{array}{l}\text { Appraised threat } \\
\text { Appraised control }\end{array}$ & $1-4$ & - & $2.2(1.2)_{\mathrm{a}}$ & $1.8(1.1)_{\mathrm{b}}$ & $2.2(1.2)_{\mathrm{a}}$ & $4.69^{\star}$ \\
$\begin{array}{l}\text { Proactive coping style } \\
\text { Self-efficacy }\end{array}$ & $1-4$ & - & $2.7(1.2)_{\mathrm{a}}$ & $3.1(1.2)_{\mathrm{b}}$ & $2.3(1.3)_{\mathrm{c}}$ & $13.21^{\star \star}$ \\
$\begin{array}{l}\text { Future temporal } \\
\quad\end{array}$ & $10-40$ & $24.4(5.3)$ & - & - & - & - \\
$\quad \begin{array}{l}\text { Grientation } \\
\text { Goal orientation }\end{array}$ & $5-25$ & $17.0(4.3)$ & - & - & - & - \\
\hline
\end{tabular}

Notes: ${ }^{1}$ These are the univariate $F$ 's calculated by the GLM repeated measures analysis. Row means with different subscripts are significantly different from each other.

${ }^{\star} p<0.05 ;{ }^{\star \star} p<0.01$. 
Ouwehand, C., Ridder, D.T.D. de, Bensing, J.M.

Situational aspects are more important in shaping proactive coping behaviour than individual characteristics: a vignette study among adults preparing for ageing.

Psychology and Health: 21, 2006, nr. 6, p. 809-825

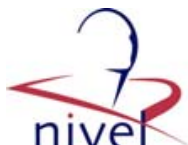

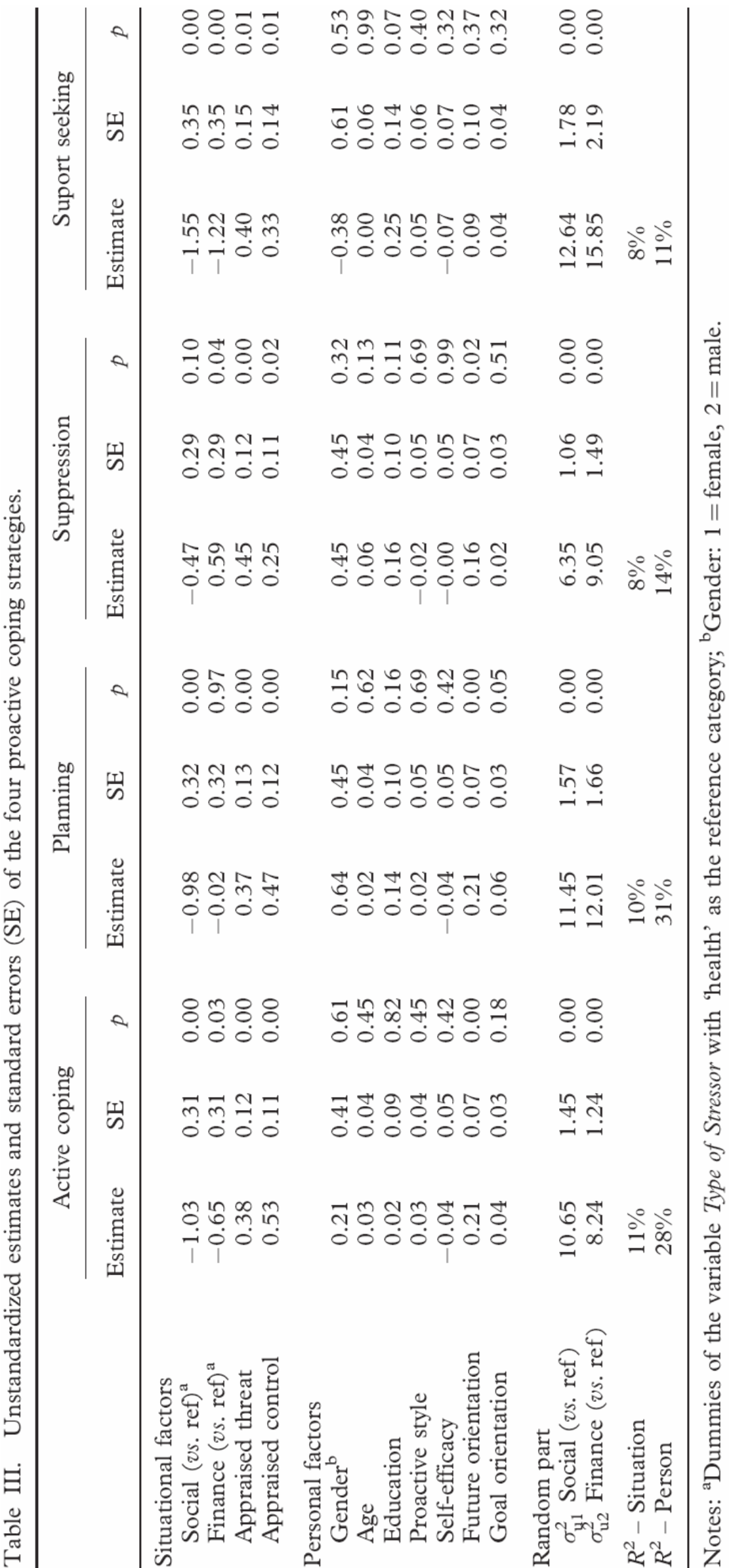

